\title{
Electromyographic Study of
}

\section{Lower Limb Muscles When Walking on Carpets}

\author{
By Ikuko Hirai*, Toshihiro Gunji*, Kazuo Maie**, Tadatoshi Yamada*** and Shiro Kondo**, Members TMSJ \\ *Faculty of Home Economics, Otsuma Women's University, Tokyo \\ **Institute of Human Living Sciences, Otsuma Women's University, Tokyo \\ ***Bridgeston Corporation, Tokyo
}

Based on the Journal of the Textile Machinery Society of Japan, Proceedings, Vol. 10, No. 10, P421-P424(1987-10)

\begin{abstract}
The characteristics of walking on carpets were inverstigated from the view point of lower limb muscle activities. Electromyograms of Musculus rectus femoris, M. tibialis anterior, $M$. gastrocnemius, and hamstring muscles of twelve female college students were recorded during the natrual walking on four kind of carpets-nylon loop pile carpet with or without jute underlay, wool cut pile carpet with or without jute underlay-and PVC tiles. The beginning point, the end point, and the duration of each muscle contraction were analysed by $F$-test, and it was found that the differences among the subjects were larger than those among the carpets. Similarly to our previous conclusion, it is concluded that the natural walking is not changed by the kinds of carpets from the view point of lower limb muscle activities and ground reaction forces.
\end{abstract}

\section{Introduction}

We investigated walking characteristics on a variety of floors and their influence on walking characteristics.

Some of the authors already reported ${ }^{[1]}$ that a carpet did not essentially change the natural walking on it from the test using a force plate. In other words, considering that the little difference in 'ground reaction force' was found between walking on the floor with carpet and that without carpet, it was concluded that some adjustment might be made in the humam-carpet system.

In this study, an experiment was made to find some adjustment in the muscle activities of the lower limb during walking naturally on the carpet using an electromyography.

Analyses hitherto conducted in the field of anthropology ${ }^{[2]}$, physical training ${ }^{[3]}$ and orthopedics ${ }^{[4]}$ have shown that differences of muscle activities have been found between bare feet and footwears, i.e., high-heel ${ }^{[5]}$. But no papers have been published on the relationship between muscle activities and floorcovering materials.

\section{Experiments and Analyzing Methods}

\subsection{Experimental apparatus and measured items}

An electromyogram of the superficial muscle is a graph recording active voltages or variance of muscular voltages generated during the contraction of skeletal muscles. In this study, a multi-purpose telemeter, Type 270, manufactured by Nippon Denki San-ei Company, was used as an electro-myograph. The specification is shown in Table 1. Bipolar surface electrodes were attached on human skin of four muscles, corresponding to fundamental movements of lower limbs during walking. The voltage was led from a transmitter, mounted at the waist of a subject to a recorder.

All measurements were made on muscles of a right lower limb-Musculus rectus femoris (which locates in front of a thigh and extends a knee joint), hamstring muscles (which locate at the back of the thigh and flex mainly the knee joint), Musculus tibialis anterior (which locates in front of a lower leg and flexes an ankle joint dorsalwards), and Musculus gastrocnemius (caput laterale) (which locates at the back of the lower leg and extend an ankle joint plantarwards), the muscles tested and their characteristics are listed in Table 2. The locations of the muscles tested are illustrated in Fig. 1.

An example of electromyograms obtained from natural walking with bare feet is shown in Fig. 2. "a-c" shows one cycle of a step, which indicates the duration of time from the right heel contact with the floor at the point "a" to the left heel contact with the floor at the point " $c$ ". " $a-b$ " shows the time of standing on the floor, which indicates the duration of time from the heel contact with the floor to the tiptoe leave from the floor at the point " $b$ ". In other words, during this period any point of the sole is in contact with the floor. Musculus rectus femoris is mainly active in two cases, one from the big toe contact with the floor to the heel leaving from the floor, and the other just before the tiptoe leaving from the floor. Hamstring muscles are mainly active just after contact of the big toe with the floor, and also before and after the tiptoe leaving from the floor. Musculus tibialis anterior is mainly active before and after the heel contact with the floor, and also just after the tiptoe leaving from the floor. Musculus gastrocnemius (caput laterale) is mainly active during the time from the heel contact with the floor to the tiptoe leaving from the floor.

Such measurements were made from the electromyograms as the period of one step, the period of the sole contact with the floor, the discharge-beginning-time of each muscle (the period from " $a$ " to the beginning of discharge), the discharge-endingtime (the period from " $a$ " to the end of discharge), and the duration of discharge. Differences among flooring materials and subjects were tested by the analysis of variance. 
Table 1 Main Specification of the electromyograph used

\begin{tabular}{l|l}
\hline Name of tester & Multi-purpose Telemeter, Type 270, manufactured by Nippon Denki-San-ei Co., Ltd. \\
\hline Number of channels & 4 \\
\hline Type of transmittance & Wireless multiple transmittance system by FM-FM \\
\hline Number of frequencies of telegraphy & B2-77.53, C2 -78.51 \\
\hline Receivable distance & Approximately $50 \mathrm{~m}$ in the open space \\
\hline Electrical power for transmitter & $006 \mathrm{P}$ battery $\times 1$ unit. Usable continuously for $48 \mathrm{hrs}$. \\
\hline Mounting method & Mountable at required place by using mouting belt \\
\hline Calibrator & Voltage checkable by using an external battery or a battery meter built in the transmitter \\
\hline Receiving antenna & Foldable rod antenna \\
\hline High-range filter & $500 \mathrm{~Hz}$ \\
\hline Output power & Voltage: $\pm 2 \mathrm{~V}(5 \mathrm{~mA}$ or less); Output resistance: $10 \Omega$ or less \\
\hline Measurement of electromyogram & 1) Time constant: 0.03 \\
& 2) Input resistance: $10 \mathrm{M} \Omega$ \\
& 3) Noise at gain $\mathrm{H}: 15 \mu \mathrm{VP}$ at $100 \mathrm{~Hz}, 20 \mu \mathrm{VP}$ at $500 \mathrm{~Hz}$ \\
& 4) Sensitivity at gain H: $500 \mu \mathrm{V} / 1 \mathrm{~A}$ \\
& 5) Maximum by input voltage $2 \mathrm{mV}$ at gain H \\
\hline Sensor & 6) Calibration voltage: $500 \mu \mathrm{V}$ \\
\hline Recorder & Disposable electrocardiograph electrode 45287, manufactured by Advance Electrode Co., \\
\hline
\end{tabular}

Table 2 Type And action of Muscles Tested

\begin{tabular}{c|c|l}
\hline & Name of Muscle & \multicolumn{1}{c}{ Action } \\
\hline A & Musclus rectus femoris & $\begin{array}{l}\text { One of Musclulus quadriceps femoris, which in general extends a knee joint. It raises a femur } \\
\text { if a lower leg is fixed. Musculus rectus femoris also flexes a crotch joint. }\end{array}$ \\
\hline B & Hamstring muscle & $\begin{array}{l}\text { Hamstring muscles pull a femur backwards, flex and rotate a lower leg outwards. They stand a } \\
\text { pelvis upright if a femur is fixed. They not only extend the femur but also flex a knee joint. } \\
\text { In addition, they rotate femur and lower leg innerwards. }\end{array}$ \\
\hline C & Musculus tibialis anterior & $\begin{array}{l}\text { It flexes a foot dorsalwards and rotates innerwards. It flexes a lower leg forwards if a foot is } \\
\text { fixed. }\end{array}$ \\
\hline D & Musculus gastrocnemius & $\begin{array}{l}\text { It extends a feet to sole (and slightly extends innerwards at the same time), or raises a heel. } \\
\text { It flexes a knee joint. It pulls backwards and supports a lower leg when standing. }\end{array}$ \\
\hline
\end{tabular}

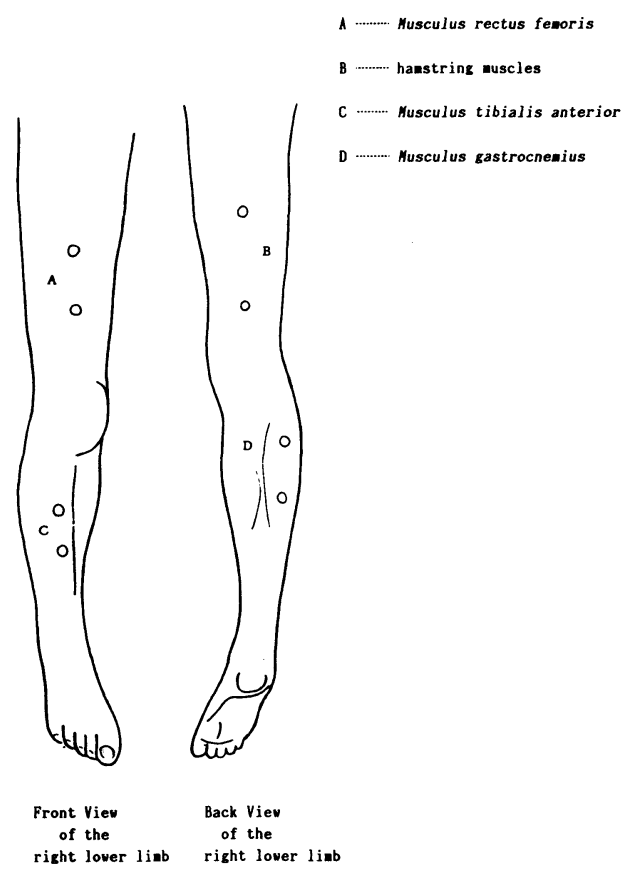

Fig. 1 Location of Muscules tested

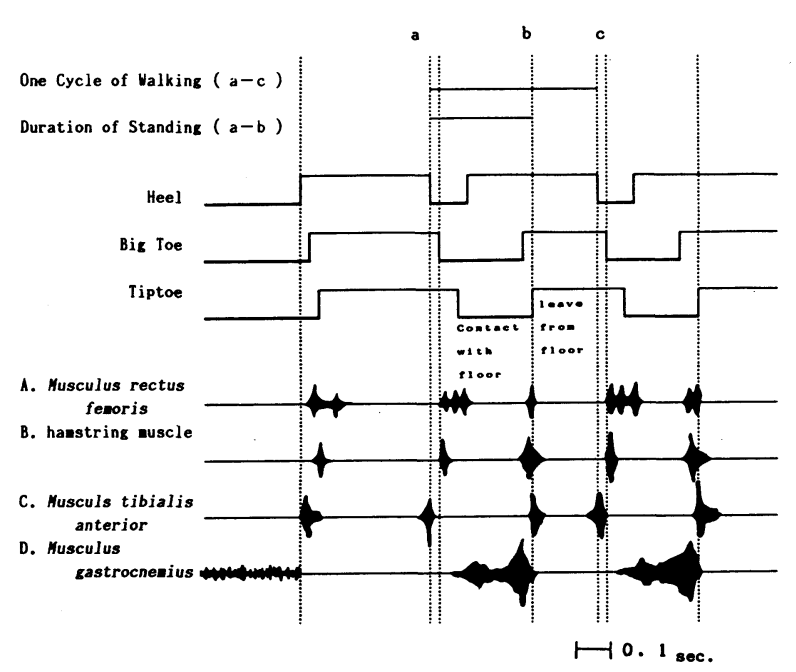

Fig. 2 Action of right lower limb when walking with bare feet

\subsection{Experimental Samples}

In the experiment, such floorcoverings were used as polyvinylchloride (PVC) tile ; wool cut pile carpets with and without underlay of flax felt, nylon loop pile carpets with and without underlay of flax felt. Bare PVC tile was used as a control. The combinations of each floor-covering are illustrated 
Table 3 Specifications of carpets and underlay for experiments

\begin{tabular}{|c|c|c|c|c|}
\hline \multirow{3}{*}{ Items Floor coverings } & \multicolumn{2}{|l|}{ Carpet } & \multirow{3}{*}{$\begin{array}{l}\text { Underlay } \\
\text { Flax felt (finished with } \\
\text { needle punching) }\end{array}$} & \multirow{3}{*}{$\begin{array}{l}\text { Floor } \\
\text { PVC tile }\end{array}$} \\
\hline & Wool cut pile & Nylon loop pile & & \\
\hline & 2.5 YR $4.5 / 3$ & $2.5 Y 5.4 / 2$ & & \\
\hline Fiber & Wool & $\begin{array}{l}\text { Nylon BCF } \\
\text { Shape of cross-section: } \Delta\end{array}$ & Flax & \\
\hline Yarn count/denier & $1 / 3.8 / \mathrm{MC}$ & $800 d / 56 f / 3 p$ & & \\
\hline Number of twists & $250 \mathrm{~T} / \mathrm{M}$ & & & \\
\hline Pile & Cut & Loop & & \\
\hline Gauge & $1 / 10^{\prime \prime}$ & $1 / 10^{\prime \prime}$ & & \\
\hline Pile height $(\mathrm{mm})$ & 8 & 4 & & \\
\hline Stitch/inch & 15 & 9 & & \\
\hline Total height (mm) & 9.5 & 6.5 & 6.9 & \\
\hline Total weight $\left(\mathrm{g} / \mathrm{cm}^{2}\right)$ & 2000 & 1650 & 1130 & \\
\hline Surface fiber weight $\left(\mathrm{g} / \mathrm{cm}^{2}\right)$ & 770 & 350 & & \\
\hline Secondary backing & Flax & Flax & & \\
\hline
\end{tabular}

in Fig. 3. The specifications of carpets and underlay are listed in Table 3.

\subsection{Subjects}

The subjects participated in this experiment were twelve female students of Otsuma Women's University. Table 4 shows their statures, weights and ages. They were $156.4 \mathrm{~cm}$ in mean stature, $47 \mathrm{~kg}$ in mean weight and 21.8 years old in mean age.

\subsection{Experimental method}

The subjects wore middle heel shoes (approximately $5 \mathrm{~cm}$ high) usually accustomed to use. A carpet of $1 \mathrm{~m}$ wide and $7 \mathrm{~m}$ long was spread on the PVC tile floor as shown in Fig. 3. The carpet and the underlay were spread so as not to slip each other. The activities of lower limb muscles were recorded during walking on the PVC tile floor and during walking on the carpet. The subjects werd asked to walk naturally. The walking speed and the cadence were left optional to each subject. The subjects walked five times under the same conditions. The analyses were made on the basis of the mean value of each test item. The walking distance on the floor per test is approximately $6 \mathrm{~m}$.

To analyze the differences among subjects and among floors, the two-dimensional cross table was made and the analysis of variance was made by $F$-test. To compensate the absolute values of each subject, all data were normalized by taking the walking cycle to be $100 \%$.

\section{Experimental Results}

Table 5 shows the results of $F$-test indicating the measured items, variance ratios, $F$-values at $5 \%$ and $1 \%$ level of significance and test results. The asterisk indicates $5 \%$ significance. The two-dimensional cross table shows that, although differences among subjects are found in each item, the differences among floors are found only in the discharge-beginningtime of hamstring muscles. However, considering that no differences are found in the discharge-ending-time and the retaining-time of hamstring muscles and that individual differences of hamstring muscles are large among muscles in walking, it is concluded that the floorcovering does not essentially affect the muscle discharge.

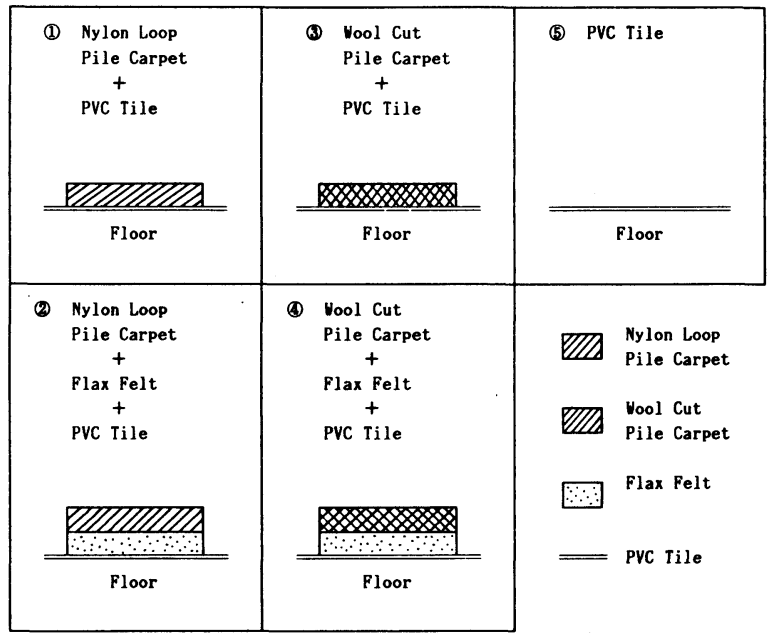

Fig. 3 Combination of flooring materials

Table 4 List of subjects

\begin{tabular}{cccc}
\hline Subject & Stature $(\mathrm{cm})$ & Weight $(\mathbf{k g})$ & Age $($ yrs. old $)$ \\
\hline YI & 162 & 50 & 23 \\
MI & 151 & 40 & 22 \\
MO & 154 & 44 & 22 \\
HK & 158 & 51 & 21 \\
MK & 156 & 50 & 22 \\
US & 153 & 42 & 23 \\
HS & 156 & 47 & 22 \\
ES & 155 & 41 & 22 \\
MH & 154 & 48 & 21 \\
KH & 160 & 52 & 21 \\
KM & 165 & 50 & 22 \\
KM & 153 & 49 & 21 \\
\hline
\end{tabular}


Table 5 Two-dimensional cross table

\begin{tabular}{|c|c|c|c|c|c|c|c|}
\hline \multirow{2}{*}{\multicolumn{2}{|c|}{$\begin{array}{l}\text { Various ratio and critical region } \\
\text { Type of muscles and discharge time (d.f. } 6,4)\end{array}$}} & \multicolumn{3}{|c|}{ Difference among subjects } & \multicolumn{3}{|c|}{ Difference among carpets } \\
\hline & & \multirow[b]{3}{*}{23.85} & \multirow{3}{*}{$\begin{array}{l}5 \% \\
6.16\end{array}$} & \multirow{3}{*}{$1 \%$} & \multirow[b]{3}{*}{1.68} & & \\
\hline & & & & & & \multirow{2}{*}{\begin{tabular}{|c|}
$5 \%$ \\
6.16 \\
\end{tabular}} & \multirow{2}{*}{$\begin{array}{l}1 \% \\
15.2 \\
\end{array}$} \\
\hline Duration of standing time & & & & & & & \\
\hline \multirow[t]{3}{*}{ Musculus rectus femoris } & Discharge-beginning-time & 7.03 & $* 6.16$ & $* 15.2$ & 3.04 & 6.16 & 15.2 \\
\hline & Discharge-ending-time & 6.59 & $* 6.16$ & 15.2 & 3.27 & 6.16 & 15.2 \\
\hline & Discharge-retaining-time & 8.74 & * 6.16 & 15.2 & 3.36 & 6.16 & 15.2 \\
\hline \multirow[t]{3}{*}{ Hamstring muscle } & Discharge-bignning-time & 29.33 & $* 6.16$ & $* 15.2$ & 6.78 & $* 6.16$ & 15.2 \\
\hline & Discharge-ending-time & 83.41 & $* 6.16$ & $* 15.2$ & 2.58 & 6.16 & 15.2 \\
\hline & Discharge-retaining-time & 8.25 & $* 6.16$ & 15.2 & 1.75 & 6.16 & 15.2 \\
\hline \multirow[t]{3}{*}{ Musculus tibialis anterior } & Discharge-bignning-time & 125.25 & $* 6.16$ & $* 15.2$ & 2.14 & 6.16 & 15.2 \\
\hline & Discharge-ending-time & 148.14 & $* 6.16$ & $* 15.2$ & 3.82 & 6.16 & 15.2 \\
\hline & Discharge-retaining-time & 11.94 & $* 6.16$ & 15.2 & 3.58 & 6.16 & 15.2 \\
\hline \multirow[t]{3}{*}{ Musculus gastrocnemius } & Discharge-biginning-time & 35.69 & $* 6.16$ & $* 15.2$ & 2.46 & 6.16 & 15.2 \\
\hline & Discharge-ending-time & 29.96 & $* 6.16$ & * 15.2 & 0.61 & 6.16 & 15.2 \\
\hline & Discharge-retaining-time & 23.48 & * 6.16 & $* 15.2$ & 2.59 & 6.16 & 15.2 \\
\hline
\end{tabular}

According to Table 5, there are Some individual differences in each muscular activity, but only one difference caused from the carpets. Therefore, it is concluded that the kinds of the carpets don't affect the human natural walking.

\section{Conclusions}

An investigation was made, using electromyographs, to find the influence of floorcovrings on the muscle activities of a lower limb during natural walking. Although significant differences are found among subjects, few differences are among floorcoverings.

A significant difference is found only among the dischargebeginning-time of hamstring muscles at $5 \%$ level. However it is difficult to conclude that the floorcovering affects the muscle activities.

As shown in the previous experiments using a force plate, this experiment using the electromyography also shows that few differences are found between the textile floorcovering and the PVC tile only in natural walking. The textile floorcovering might not change essentially the human walking.

This article was prepared on the basis of the paper presented at the 40th annual conference of the Textile Machinery Society of Japan held on June 1987.

\section{References}

[1] Maekawa, Gunii, Maie, Kondo; J. Text. Mach. Soc. Jpn. (in Japanese), 38, P533 (1985).

[2] S. Kondo; J. Anthropology ( in Japanese ), 62, P121 (1952). S. Kondo; Anthropological Study on Human Posture and Locomotion, J. Faculty of Science Univ. Tokyo, Sec. V.2, P189 (1960).

[3] S. Ikeda; Nissei Kaishi ( in Japanese) 46, P323 (1972). S. Goto, et al.; Annals of Health Science and Physical Education (in Japanese), Osaka City University, 11, P55 (1976). S. Goto, et al.; Annals of Health Science and Physical Education (in Japanese), Osaka City University, 13, P39 (1978). S. Goto; J. Jpn. Res. Assn. Test. End-Uses (in Japanese) 28, P143 (1987).

[4] K. Fujikawa; Acta Medica (in Japanese), 33-4, P422 (1963)

[5] S. Kondo; Essay on Feet ( in Japanese, Iwanami Book, P89 (1979).

[6] Dewa, Morishita; J. Jpn. Res. Assn. Test. End-Uses, 10, P437 (1969). 